\title{
Reflection and Reconstruction of the Concept of Rumor
}

\author{
Fengming Liu, Chunhua Gao
}

Business School, Shandong Normal University, Jinan, China

Keywords: rumor; Internet rumor; definition; keyword database.

\begin{abstract}
Rumor is a kind of complex social phenomenon. With the help of the Internet, rumors spread faster and have a wider range of influence. However, the definition of rumor varies, and it is only suitable for specific social environment and practical application, which is not accepted by academic circles. To meet the needs of academic research, it is urgent to define the connotation of rumors and give a standardized and unified definition. Firstly, this paper collects and sorts out some concepts of rumor and definition of Internet rumors, analyzes and sorts out the key elements among them, and constructs a rumor keyword database. Secondly, it summarizes the overall characteristics of rumors and puts forward an adaptive definition of rumors, which lays a foundation for the academic research of rumors.
\end{abstract}

\section{Introduction}

Rumor is an ancient and mysterious existence, which is produced almost at the same time with human civilization. In the long history of human development, rumors have never been absent. Especially during the Second World War, rumors forced people to face and reflect on the existence of rumors. Since then, people's research on rumors has really begun, and has been deepening in the process of social development and progress. Experts and scholars at home and abroad pay more attention to the identification, dissemination and governance of rumors, and rarely do in-depth study on the definition of rumors. Gengyun Xie et al. [1] studied the definition of rumor by foreign experts and scholars, discussed the definition of rumor and discrimination of related concepts of rumor, public opinion and propaganda;Xia Lei[2]studied the original meaning , use and evolution of rumors, and put forward a new definition of rumor on the basis of discussion and summary; Anping Zhou[3]pointed out that the spread of rumors will have negative consequences, which will bring about negative consequences for man. According to Hua Lin[4], Internet rumors have become the focus of public attention, and can be better dealt with on the basis of clarifying the concept and scope of Internet rumors.

\section{Rumor and Internet rumors}

\subsection{Rumor}

Rumor originated in the long history of the development of human civilization, with a long history and everlasting innovation. The word "rumor" is commonly used in the study of rumors abroad. It may be translated into "rumor", "hearsay" or "gossip" in China. Some scholars think that the three meanings are different and should be distinguished, while others do not agree. Most of the definitions of rumors are put forward by scholars in specific research background or practical application situation. In the traditional rumor research, different scholars have different opinions on rumor. They define rumor from different angles. There is no unified definition of what rumor is. Although the definition of rumor is different, with the evolution of history, the connotation of rumor essence is interlinked. From the most obvious effect, rumor "gives people informational and emotional satisfaction" .

In the Rumor in Han Dynasty, Zongli Lv[5]pointed out that songs and ballads are rhymes, which are catchy and easy to spread orally. However, most of the ballads are spread among illiterate or low educated groups such as common people and children, and the terms are more popular and easy to 
remember. Historical documents since the book of the Latter Han Dynasty often refer to such folk or unofficial ballads as "rumors". They are a form of rumor in Chinese history. Compared with gossip, falsehood and rumor, rumor is easier to spread and has more extensive influence because of its rhyme form.

Knapp[6]believes that rumors are "a declaration intended to make people believe that it is related to current events and widely circulated without official confirmation." Allport and Postman [7] believe that rumor is a "proposition related to the events at that time, in order to make people believe that it is generally spread among people by means of oral media, but there is no specific information to confirm its accuracy." Peterson and Gist [8] believe that rumor is "an unsubstantiated statement or interpretation of a thing, event or issue of public interest that is circulated privately among people." Shibutani [9] believes that the rumor is "a description, language or explanation formed in informal communication, which is not confirmed by official information, but is seriously accepted by most interested groups." Michelson and Molly[10]believe that "a rumor is a conversation whose authenticity has not been confirmed by the disseminator himself or by relevant evidence." Edgar Morin[11] believes that "rumors are information related to current affairs that are popular in certain social circles, and usually have no factual basis and are not spread in the mass media." Kapferer [12] believes that rumors are a "proposition related to the events of the time, in order to make people believe that they are generally spread among people by means of oral media, but there is no specific information to confirm its accuracy", and "widely spread without official confirmation". Yu Hu[13] believes that "a rumor is an unproven exposition or interpretation of an object, event or problem of public interest spread through public or non-public channels." There are also scholars with similar views, such as Huabao Zhang[14], Shenghong Jiang [15], Jianwen Guan [16], Lianxiang Sha [17], Lingfei Tang [18], Min Luo[19], and other scholars. They all believe that the unified feature of rumors is that they are "not officially confirmed / have no factual basis / incomplete information" on the basis of wide spread, that is to say, the authenticity of rumors cannot be confirmed, and the definition of rumors is neutral.

However, many scholars believe that rumors, whether true or false, are harmful. Schachter and Burdict [20] believe that "rumors are untrustworthy, and they are a kind of distorted communication that uses the effect of spreading or spreading to secretly and quickly transmit between interpersonal interactions." Ronghua Shi [21] also pointed out that rumors are "hearsay without factual basis, deliberately fabricated and teach orally news. Some rumors are defamatory and some are exaggerated. " Jianming Liu [22] believes that "a rumor is a factual description without any basis and has a defamatory opinion direction. Therefore, it is not a neutral rumor, but a negative public opinion of criticism." Ying Wang [23] believes that "rumors often refer to malicious attacks, which are false news deliberately fabricated and spread by the makers." The definition of rumors focuses on the negative effects of rumors, believing that rumors are "harmful / deliberately fabricated", even if the information spread by some rumors is later proved to be true.

\subsection{Internet rumors}

According to the 54th statistical report on China's Internet Development released by China Internet Network Information Center (CNNIC), as of March 2020, the number of Internet users in China was 904 million, and the penetration rate was 64.5\% [24]. With the rapid development of the Internet, the spread of Internet rumors has become increasingly rampant. Internet rumors spread rapidly and widely, endangering social stability. Although the public dislike Internet rumors, many netizens do not know the definition of Internet rumors, Different people will have different views on the definition of Internet rumors. It is difficult to have a specific definition of what is the legitimate freedom of speech on the Internet and what touches the spread of improper Internet rumors. Therefore, it is necessary to have a clear definition of Internet rumors.

Some scholars think that the Internet factors are added to the traditional definition of rumors, which makes the rumors spread rapidly in the new network environment, and the influence is more difficult to estimate, but the authenticity can not be identified, so the definition of network rumors is neutral. Yanni Shen[25] believes that Internet rumors are believed information spread by Internet 
users through personal websites, e-mails and electronic bulletin boards (including electronic bulletin boards, electronic forums, network news groups, and message boards in online chat rooms). They are generally related to topics that people are interested in and spread through the Internet without definite basis.Naipeng Chao[9] believes that Internet rumors are unproven statements or interpretations of things, events or problems that netizens are interested in, which are spread by Internet users in a specific way in the specific environment of the Internet. Guixing Ke [26] believes that Internet rumors refer to information that is spread on the Internet without real basis, or has not been verified, and it is difficult for the public to distinguish the authenticity. Qiang Chen [27] believes that Internet rumors are information spread through the Internet without official confirmation or have been refuted by the government. Shiyan Hu [28] believes that Internet rumors refer to the words without factual basis that are widely spread through the network media - e-mail, online chat tools, social networking sites, blogs, microblogs, etc., mainly involving emergencies, public sphere, organizations, celebrities' privacy, etc. Scholars with similar views include Jianwen Guan [16], Xiaoyi Jiang[29], Shuliang Bai [30], Wenchao Li [31], Guohua Wang [32], Weina Zuo [33], etc. They all believe that Internet rumors are widely spread through the unified medium of the Internet, and the authenticity cannot be verified, but the definition of rumors is not derogatory.

However, many scholars hold different views. Ying Wang [23]believes that Internet rumors refer to malicious information spread through the network and fabricated by the manufacturer. Can Bai[34] thinks that according to the background, environment and other factors, network rumors can be defined as: in the relatively lack of information, the existence of unsafe factors in society and the virtual environment of the network, the information that has not been verified is released and spread on the Internet, which leads to a wide range of circulation among Internet users, thus causing adverse social impact. Yongjiang Xie [35] defined Internet rumors as false information generated or released and spread on the Internet without factual basis or fabrication. Jingbao Li[36] believes that in the Internet environment, the words, information and opinions that are disseminate or spread through microblogs, wechat, social networking sites, online forums and other network media without basis or confirmation, and have a great negative impact on individuals, collectives, society or countries, and have no factual basis. Xiaohui Deng [37], Juhua Jing[38] and other scholars also agree with the above views. They believe that rumors, especially Internet rumors, are generated and spread with a certain purpose without considering their authenticity. Combined with the catalyst of the Internet, it will certainly have a negative impact on society and even affect social stability.

\section{Key words in rumor definition}

In this paper, we searched the literatures of HowNet from 2004 to 2019, sorted out and summarized the definition of rumor in the retrieved articles, manually eliminated the rumor definition items with incomplete data information, sorted out 66 pieces of rumor definitions, manually extracted the corresponding keywords, formed the keyword database of rumor definition, and further studied the centralized characteristics of rumor definition.

The keyword database (keyword frequency $\geq 3$ ) is shown in Table 1 and Figure 1.

Table 1.Key words and word frequency statistics

\begin{tabular}{|c|c|c|c|c|c|}
\hline Serial Number & Key Words & $\begin{array}{c}\text { Word } \\
\text { Frequency }\end{array}$ & Serial Number & Key Words & $\begin{array}{c}\text { Word } \\
\text { Frequency }\end{array}$ \\
\hline 1 & spread & 26 & 19 & elaboration & 4 \\
\hline 2 & information & 21 & 20 & untrue & 4 \\
\hline 3 & news & 21 & 21 & truthfulness & 4 \\
\hline 4 & unproved & 15 & 22 & object & 4 \\
\hline 5 & according to & 15 & 23 & (unable to) confirm & 4 \\
\hline 6 & fact & 14 & 24 & deliberately & 4 \\
\hline 7 & society & 13 & 25 & basis & 4 \\
\hline 8 & circulate & 11 & 26 & purpose & 4 \\
\hline 9 & fabrication & 9 & 27 & false & 4 \\
\hline
\end{tabular}




\begin{tabular}{|c|c|c|c|c|c|}
\hline 10 & event & 8 & 28 & scatter & 4 \\
\hline 11 & (be) interested & 8 & 29 & make people believe & 4 \\
\hline 12 & public & 8 & 30 & environment & 4 \\
\hline 13 & specific & 8 & 31 & language & 3 \\
\hline 14 & hearsay & 7 & 32 & $\begin{array}{c}\text { interpersonal } \\
\text { relationship }\end{array}$ & 3 \\
\hline 15 & $\begin{array}{c}\text { not officially } \\
\text { confirmed }\end{array}$ & 6 & 33 & masses & 3 \\
\hline 16 & speech & 6 & 34 & crowd & 3 \\
\hline 17 & annotation & 5 & 35 & & \\
\hline
\end{tabular}

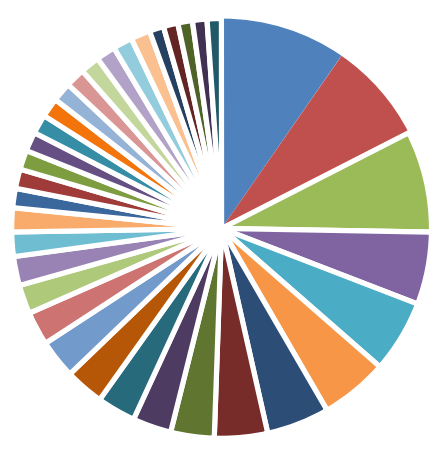

\begin{tabular}{|c|c|c|}
\hline spread & = information & news \\
\hline unproved & according to & a fact \\
\hline - society & - circulate & - fabrication \\
\hline w event & - (be) interested & - public \\
\hline specific & wearsay & not officially confirmed \\
\hline speech & annotation & problem \\
\hline - elaborate & antrue & a truthfulness \\
\hline m object & - (unable to) confirm & - deliberately \\
\hline m basis & purpose & false \\
\hline w scatter & make people believe & w environment \\
\hline - language & - interpersonal relationship & घroup \\
\hline crowd & - people & \\
\hline
\end{tabular}

Figure 1.Keyword frequency chart

The first characteristic of rumor is information. According to the above induction and collation, it is not difficult to find that the frequency of "information" is 21, and that of "news" is 21, including 20 items of "speech, annotation, problem, elaboration, etc"., which reflects the informativeness of rumors. In essence, rumors are information, which can be stored, expanded, transmitted and effective in a specific range. The spread of rumors needs carriers. From the initial word of mouth, to the later newspapers, and finally to the new media network, rumors must be stored and spread by some carrier.People can add their own understanding or distortion in the process of spreading, and constantly expand the content of rumors, enrich the connotation of rumors and expand the denotation of rumors, enhance their credibility and dissemination ability. Information has certain timeliness, and rumors can have the greatest impact in a specific period and scope.

The second characteristic of rumor is confirmability. The frequency of "unproved" is 15 , and that of "not officially confirmed" is 6,and that of "unable to confirm" is 4, and that of "informal" and "unofficial" is 3.It embodies the second characteristic of rumors -confirmatory.Rumors are unconfirmed news.Verifiability refers to the possibility of confirmation. The determination of the truth or falseness of a piece of news can appear both in the current experience and in the future practical experience. In a word, the authenticity of information can be verified. The confirmation here refers to the official information officially released by the government and other official departments to falsify, reflecting the credibility of the government and other authoritative departments. 
The third characteristic of rumor is communication. The word frequency of "spread" is 26, that of "circulate" is 11 , and that of "scatter" is 4 . The rumor is an unconfirmed and widely spread news. Communication is a part of the operation of social information system. People exchange information through corresponding symbols and media, resulting in corresponding changes. The spread of rumors is essentially an activity of information sharing. In the era of information explosion, people are eager for information exchange and communication, so they will also have the desire to spread, especially rumors, which have not been proved fuzzy and uncertain .Therefore, the spread of rumors is an indispensable feature.

The fourth characteristic of rumors is eventuality. The word frequency of "event" is 8 and that of "object" is 4, which shows that rumor is a piece of news which is connected with the event of public interest and has not been confirmed and widely spread. The emergence and spread of a rumor has its social background and environment. The occurrence of social major events will inevitably accompany the generation and spread of rumors.Since the outbreak of novel coronavirus pneumonia, rumors and gossip about epidemic situation, false prevention and control have spread on the Internet,such as drinking and Acyclovir can prevent new coronavirus.The epidemic situation causes rumors such as global shortage of essential drugs and causes netizens to go crazy. It will not only lead to misunderstanding and misreading of Internet users, but also cause social panic, which seriously affects social order and is not conducive to the development of epidemic prevention and control.

The fifth characteristic of rumors is lack of factual basis. The frequency of the key words of "according to" is 15 , that of "basis" is 4 , that of "fact" is 14 , that of "untrue" and "truthfulness" is 4 , and that of "false" is 4, which shows that the rumor is related to the event of public interest, lacks of factual basis and is widely spread without confirmation. "According to and basis" means the foundation,taking something as the basis, Sima Guang said in his "On the temple" that "things can not be seen, it is difficult to be based on". Rumors do not matter whether they are true or false, and there is no need to have a basis for generation and dissemination. Rumor makers have their specific purposes and motives, and spread information without factual basis to achieve a certain purpose, so rumors are generated .There is a lack of factual basis, which is obvious.

In addition to the above characteristics, rumors also have certain seditious and social characteristics. The sixth characteristic of rumors is closely related to the people. The frequency of keywords for "society" is 13, "environment" is 4, "public" is 8, "making people believe" is 4, "masses", "crowd" and "people" are all 3, " (be) interested" is 8, "fabrication" is 9, and "deliberately" is 9 ,the word frequency of "deliberately"is 4 . Being related to people means that social factors must be taken into consideration. The existing social environment is the soil for rumors to spread rampantly. Especially, the occurrence of major emergencies will inevitably lead to rumors and emerge in endlessly. Rumors are regarded as a common social psychological phenomenon and a reflection of public psychology. When a rumor can make the contacts of the rumor produce psychological resonance and identity or arouse the interest of inquiry, it is extremely inflammatory, and it is very easy to spread and spread rapidly in a short time, causing adverse effects in the society.

The sentiment analysis of the above rumor definitions is shown in Figure 2. According to the definition of rumor in different social backgrounds and application situations, the emotional analysis results show that $75 \%$ of the keywords are neutral and $20 \%$ of the keywords are negative. Most of the definitions of rumors are defined as neutral, that is to say, the authenticity of the content contained in rumors can not be verified and there is no basic factual basis. The essence of rumor spreading is the sharing of social information. However, in reality, there are also rumors deliberately or maliciously fabricated, such as disaster rumors and network political rumors. In order to achieve specific needs, individuals or groups spread unfounded news, causing people's psychological and behavioral panic and affecting the normal social order. 


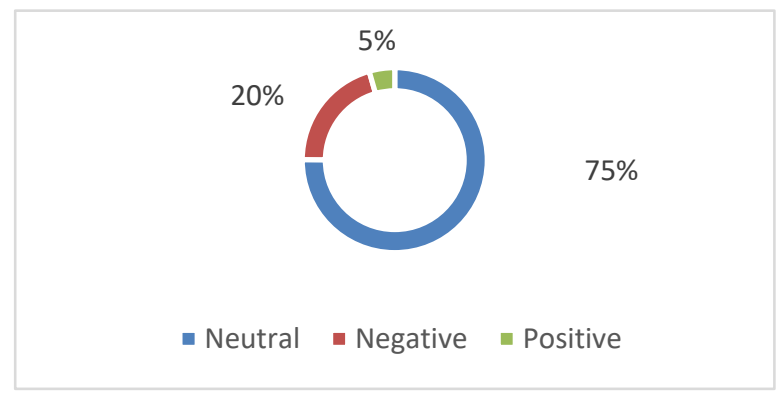

Figure 2. Emotional analysis of key words in rumor definition

The evolution and development process of the definition of rumor shows the richness of the definition of rumor, which is reflected in the fact that the concept of rumor can change according to its background. But the essence of the concept of rumor can be summed up as follows: (1) information; (2) confirmatory; (3) communication; (4) eventuality; (5) lack of factual basis; (6) seditious and social characteristics.

Based on the above discussion, this paper defines the rumor as follows: A rumor is a kind of information which is generated on the background of a certain social event, can stimulate public interest, lack of factual basis and is widely spread without confirmation.

\section{Conclusion}

The Internet has greatly subverted the traditional mode of information dissemination. In the era of we media, everyone may become a participant in the spread of Internet rumors, which is more anonymous and secure. Internet rumors have been paid more and more attention by people. The rumors of major emergencies such as disaster rumors and political rumors are also emerging in an endless stream. At the same time, they have greater destructive power and influence. They endanger social rank order and affects social stability. Therefore, the definition of rumor connotation and the extraction of characteristics provide support for the control and governance of Internet rumors in the era of big data.

\section{References}

[1] Xie Yungeng,Fu Xiang, Pan Yu, Liu Lu, Ji Yannan, Liu Cong. A Review of Overseas Rumors [J]. New Media and Society,2015(04):37-57.

[2] Lei Xia. Rumor: Concept Evolution and Development [J]. Journalism and Communication Research,2016,23(09):113-118.

[3] Zhou Anping. Discussion on the Concept of Rumor Normalization [J]. Political and Legal Issues,2015(06):70-78.

[4] Lin Hua. Deconstruction and Reconstruction of the Concept of Internet Rumors [J]. Research on Network Information Law,2017(02):139-153+217.

[5] Lu Zongli. Rumor in Han Dynasty [M]. ZheJiang University Press, 2011.

[6] Knapp R., “A Psychology of Rumor,” Public Opinion Quarterly,8（1），1944， pp.22-37.

[7] Gordon W.Allport \& Leo Postman, “An Analysis of Rumor, " The Public Opinion Quarterly,vol.10,no.4(1946-1947),pp.501-507.

[8] Warren A.Peterson \& Noel P.Gist “Rumor and Public Opinion,” American Journal of Sociology,vol.57,no.2(1951) , pp.59-167.

[9] Chao Naipeng, Huang Xian. Research on "Rumor" Phenomenon in Network Communication [J]. Information Theory and Practice,2004(06):586-589. 
[10] Michelson G , Mouly S . Rumour and gossip in organisations: a conceptual study[J]. Management Decision, 2000, 38(5):339-346.

[11] Morin E.,La rumeur d’ Orleans,1969,Paris:Le Seuil Editions,Quoted in J.N.Kapferer,A Mass Poisoning Rumor in Europe,The Public Opinion Quarterly,vol.53,no.4(1989),pp.467-481.

[12] Kapferer. Rumor [M]. Shanghai: Shanghai People's Publishing House,1991.

[13] Hu Yu. Effect of Mass Communication. Beijing: Xinhua Publishing House, 2000.

[14] Zhang Huabao. Social Psychology. Taipei: Sanmin Publishing House, 1994.

[15] Jiang Shenghong. Formation, Transmission and Public Opinion Guidance Mechanism of Internet Rumors [J]. Chongqing Social Science,2012(06):12-20.

[16] Guan Jianwen. Building an Effective Mechanism to Prevent and Stop Internet Rumors [J]. News Front,2006(11):65-67.

[17] Sha Lianxiang. Reflection on the Nature of Social Psychology. Social Psychology Science,2006(01):11-16.

[18] Tang Lingfei. Reflections on Social Rumors in the Information Age [J]. Theory Guide,2008(12):47-49.

[19] Luo min, Zhang Ping. Psychological Causes and Countermeasures of Political Rumors [J]. Legal System and Society,2008(25):200-201.

[20] Chao Naipeng, Huang Xian. Research on "Rumor" Phenomenon in Network Communication [J]. Information Theory and Practice,2004(06):586-589.

[21] Shi Ronghua. Dictionary of Social Psychology [M] Sichuan People's Publishing House,1988.

[22] Liu Jianming. Public Opinion Communication. Beijing: Tsinghua University Press, 2000.

[23] Wang Ying, Xue Ruiping, Jiang Wenjie, Huang Jinjin, Fan Jing. Viewing the Attitude and Psychology of Internet Users from Internet Rumors -- Taking "AIDS Girl Incident" as an Example [J]. Scientific and Technological Information,2010(10):431-432.

[24] Statistical Report on the Development of Internet in China[EB/OL].http:Mwww.cnnic.cn,2020-04-28.

[25] Shen Yanni. Research on the Spread of Internet Rumors [J]. Southeast Communication,2008(12):60-61.

[26] Ke Guixing, Chi Yukai, Wang Bo. Communication Mechanism and Coping Strategies of Internet Rumors in Extraordinary Times [J]. Social Psychology Science,2009,24(01):29-33.

[27] Chen Qiang, Fang Fujian, Xu Xiaolin. Diffusion Dynamics and Resolution of Internet Rumors: A Case Study of Earthquake Rumors [J]. Library and Information Work,2010,54(22):29-33.

[28] Hu Shiyan. Mechanism Analysis and Decision Control of Internet Rumors [J]. Leadership Science,2012(23):29-31.

[29] Jiang Xiaoyi. Internet Rumors: Rumors with Wings [J]. Internet Wealth,2009(09):181-182+220.

[30] Bai Shuliang. Research on the Causes and Countermeasures of Internet Rumors [J]. Press,2010(04):82-83.

[31] Li Wenchao. Research on the Spreading Mechanism of Internet Rumors in Public Crisis [D]. East China Normal University,2010. 
[32] Wang Guohua, Fang Fujian, Chen Qiang. Transmission of Internet Rumors: Process, Motivation and Root Cause -- Taking Earthquake Rumors as an Example [J]. Journal of Beijing University of Technology (Social Science Edition),2011,13(02):112-116.

[33] Zuo Weina. Research on the Spread of Internet Rumors [D]. Graduate School of Chinese Academy of Social Sciences,2006.

[34] Bai Can. Research on the Generation and Governance of Internet Rumors [J]. Journal of Huaibei Vocational and Technical College,2012,11(06):28-29.

[35] Xie Yongjiang, Huang Fang. On the Legal Regulation of Internet Rumors [J]. Journal of National Institute of Administration,2013(01):85-89.

[36] Li Jingbao, Dai Shuiping. Comprehensive Management of Internet Rumors [J]. Journal of China JingGangshan Cadre College,2017,10(03):131-140.

[37] Deng Xiaohui. Research on the Criminal Law Regulation of Internet Rumors [J]. Legal System Expo,2017(15):247.

[38] Jing Juhua, Hu Weixi. Analysis on Countermeasures of Internet Rumors Governance from the Perspective of Media Convergence [J]. Social Science Trends,2018(11):39-42. 